\title{
Effect of Operating Conditions of the Extraction Process on the Physical Properties of Lubricating Oil
}

\author{
Amirhossein Mehrkesh ${ }^{1, *}$, Touraj Tavakoli ${ }^{2}$ and Mohammad S. Hatamipour ${ }^{2}$ \\ ${ }^{1}$ Department of Civil Engineering, University of Colorado Denver, Denver, CO, USA \\ ${ }^{2}$ Department of Chemical Engineering, University of Isfahan, Hezar-Jerib Avenue, Isfahan, Iran
}

\begin{abstract}
Lubricating base oil is commonly extracted from lube-oil cut, a petroleum cut, with the use of an aromatic solvent. Aromatic content of the final product is an important criterion specifying the product quality. The aromatic removal process to produce the lubricating oil should be carried out in a Liquid-Liquid extraction column. In a typical solvent extraction process, solvent to feed ratio, solvent and feed temperatures, agitation rate, and settling time could directly affect the yield of extraction. In the current study, the effect of agitation rate and settling time on the yield of extraction was studied. It was found that a settling time of $2 \mathrm{hrs}$ and an agitation rate of 430 RPM to be the optimum parameters of the extraction process.
\end{abstract}

Keywords: Lubricating oil, Liquid-Liquid Extraction, Optimization.

\section{INTRODUCTION}

Lubricating oils are one of the main products of an oil refinery. Nowadays, to decrease the adverse effects of friction forces, demand for lubricating oil is increasing significantly [1]. Manufacturing of lubricating base oils requires the aromatic compounds to be extracted to some extent from the lube oil cut resulting in having a better quality product [2-4]. The lube oil cut is a petroleum cut mainly separated from heavy fractions of a vacuum distillation tower. Lube oil cuts normally contain aromatic and saturated (naphthenic and paraffinic) compounds. Several works have been done in selecting an efficient solvent for this extraction process [5]. An appropriate solvent should maximize the difference in the properties of two immiscible phases [3, 9]. Furfural is one of the most widely used solvents that its selectivity toward aromatics is high enough. Furfural selectivity will decrease slowly when temperature increases, making it an acceptable choice for both light and heavy vacuum distillates $[6-8,10]$. In order to separate aromatic compounds from the lubeoil cut, solvent and feed should be placed in contact to each other in a mixer-settler. A proper agitation rate (to create a sufficient contact area) as well as an adequate settling time could result in producing two immiscible liquid phases. The light phase, raffinate, is enriched of linear and cyclic saturated hydrocarbons (paraffinic and naphthenic) whereas the heavier phase, extract, is enriched of solvent and aromatics which is later transported to a solvent recovery unit. Simulation of the extraction process can be done via empirical methods

*Address correspondence to this author at the Department of Civil Engineering, University of Colorado Denver, Denver, CO, USA;

E-mail: amirhm62@gmail.com
[11]. Among all alternative processes to produce lubricating oils, solvent extraction has received considerable attention [12-15]. Since it is not possible to identify all the components of a complex hydrocarbon mixtures, its composition should be defined through empirical methods [16]. The pseudocomponents approach based on distillation curves [17] used in the vapor- liquid equilibrium calculations is not effective for LLE modeling. De Lucas et al. [7] have applied the pseudo-component approach to predict the LLE for the systems furfural + lubricating oil systems. To determine the composition of complex hydrocarbon mixtures, standard test methods such as ASTM D2007 [18] might be used. However, since these methods are time and money consuming, the composition of petroleum mixtures is usually determined via measuring the physical properties. These properties can all be measured experimentally, but some of them are normally estimated through well-known correlations [9]. Several studies have proposed precise correlations which help us predict the composition of hydrocarbon mixtures (aromatic, naphthenic and paraffinics compounds concentrations) using their refractive index (RI) and viscosity [19]. ASTM D3238 [20] standard test method can be used to characterize the petroleum cuts. According to this test, density at $293 \mathrm{~K}\left(\mathrm{~d}_{293}\right), \mathrm{RI}$ at 293K $\left(\mathrm{Rl}_{293}\right)$, molecular weight and Sulfur content (\%S) of the samples can be used to define the distribution of aromatics (A), naphthenic $(N)$ and paraffinic $(P)$ compounds in a given sample. Solvent to feed ratio, solvent and feed temperatures, agitation rate and settling time are considered to be the main parameters affecting the yield of extraction. Process temperature can influence the equilibrium condition of the system. Although, increasing the solvent to feed ratio may result in having a higher yield of extraction, using too 
much of solvent can transfer more amount of hydrocarbons (both aromatics and aliphatics) from feed to the extract phase resulting in production of a low quality lubricating oil having a low viscosity value [20]. In this study, operating temperature and solvent to feed ratio were kept unchanged to investigate the effect of agitation rate and settling time on the yield of. De Lucas et al. [7] reported $2 \mathrm{hrs}$ of agitation at 280 RPM and 15 min of settling. Singh and Kishore [2] used a 30 min of agitation and $2 \mathrm{hrs}$ of settling. In the current work, $1 \mathrm{hr}$ of agitation at 350-550 RPM and 1-3 hours of settling time were used.

\section{MATERIAL AND METHODS}

In this experimental work, furfural and Lube-oil cut were provided by Sepahan Oil Co. Furfural solvent was applied to extract the aromatic hydrocarbons from lubeoil cut for producing a higher quality lubricating baseoil. The physical properties of the lube-oil cut and furfural are listed in Table 1.

Table 1: Physical Properties of Lube Oil Cut and Furfural.

\begin{tabular}{|c|c|c|}
\hline & Furfural & Lube Oil Cut \\
\hline \hline Density, at $20^{\circ}{ }^{\circ},\left(\mathrm{g} / \mathrm{cm}^{3}\right)$ & 1.1598 & 0.9257 \\
\hline Viscosity, at $25^{\circ},(\mathrm{CP})$ & 1.49 & 445 \\
\hline Flash point $\left({ }^{\circ} \mathrm{C}\right)$ & 61.7 & 258.3 \\
\hline Molecular weight & 96 & 467 \\
\hline $\mathrm{RI}$, at $20^{\circ} \mathrm{C}$ & 1.5261 & 1.5208 \\
\hline $\mathrm{C}_{\mathrm{A}} \%$ & - & 25 \\
\hline $\mathrm{C}_{\mathrm{N}} \%$ & - & 11 \\
\hline $\mathrm{C}_{\mathrm{P}} \%$ & - & 64 \\
\hline
\end{tabular}

$\mathrm{C}_{\mathrm{A}}, \mathrm{C}_{\mathrm{N}}$ and $\mathrm{C}_{\mathrm{P}}$ are the mass basis concentration of aromatic, naphthenic and paraffinic compounds, respectively.

Furfural can react with oxygen; therefore the furfural solvent was distilled before using it for aromatic removal. The entry furfural had the purity of $98 \%$ as it was tested by a Gas Chromatography (GC) approach.

The extraction process was carried out in an experimental setup which was composed of a cylindrical stirred glassy tank equipped with a valve to able us remove the extract phase, a thermostatic bath (Shimifan S-57) with a temperature controlling system within $\pm 0.1^{\circ} \mathrm{C}$, a cylinder containing nitrogen, and a variable speed agitator shown in Figure 1.

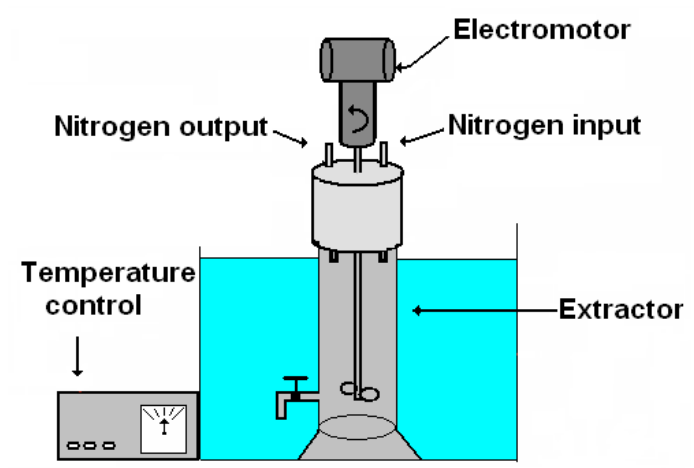

Figure 1: A Schematic of the experimental setup.

This experimental study was designed to investigate the effect of agitation rate and settling time on the yield of separation. For this purpose two operational parameters, temperature and solvent to feed ratio were kept constant at $338 \mathrm{~K}$ and $1.5(\mathrm{Vol} / \mathrm{Vol})$, respectively. On the next step furfural and lube cut were mixed together under the agitation rate of 350,450 and 550 RPM in three different experimental batches. Taking samples from the immiscible raffinate and extract phases was performed in 3 different times, 1, 2 and 3hrs. A nitrogen $\left(\mathrm{N}_{2}\right)$ stream was purged into the batch during the experiment to avoid the oxidation of furfural. After the formation of two immiscible phases, furfural was removed from both extract and raffinate phases by vacuum distillation. In order to investigate the effect of agitation rate and settling time on the yield of extraction, a 3 level method of design of experiments (DOE) was used. Based on a full factorial approach by having 2 factors and 3 levels, $3^{2}=9$, experimental runs were needed. The refractive index (RI) and density of the samples were also measured at $20^{\circ} \mathrm{C}$. In addition to that the kinematic viscosity of the samples was measured at $37.8^{\circ} \mathrm{C}$ and $98.89^{\circ} \mathrm{C}$ to calculate the molecular weights based on ASTM D 2502-04 [21]. This test makes use of a graphical method to determine the molecular weight (MW) using the viscosity of the samples. Aromatic, naphthenic and paraffinic content of the samples was determined by ASTM D-3238 [20]. Automatic self-heated Refractometers are usually used for high temperature processes, especially in the food industry, petrochemical industry, and oil refineries. In current study a refractometer (Index instrument Inc., GPR 1137-E model) was used to measure the refractory index (RI) of samples. The accuracy of this refractometer was set to be 0.00001 .

A rotational Viscometer (Anton Paar Co., SVM 3000 Stabinger model) was used to measure the dynamic viscosity and density of raffinate and extract samples 
Table 2: Characterization of the Raffinate Samples

\begin{tabular}{|c|c|c|c|c|c|c|c|c|c|c|}
\hline Run\# & $\begin{array}{l}\text { Agitation Rate } \\
\text { (RPM) }\end{array}$ & $\begin{array}{l}\text { Settling } \\
\text { Time } \\
\text { (hour) }\end{array}$ & Raffinate (ml) & $\begin{array}{c}\text { Extract } \\
(\mathrm{ml})\end{array}$ & $\mathbf{R I}_{20}$ & $\begin{array}{l}\text { Density } \\
\left(\mathrm{g} / \mathrm{cm}^{3}\right)\end{array}$ & $\% S$ & $\% \mathrm{C}_{\mathrm{A}}$ & $\% \mathrm{C}_{\mathrm{N}}$ & $\% \mathrm{C}_{\mathrm{P}}$ \\
\hline 1 & 550 & 1 & 103.0 & 172.0 & 1.50167 & 0.8877 & 1.65 & 19.6 & 5.3 & 75.1 \\
\hline 2 & 550 & 2 & 101.7 & 173.3 & 1.49935 & 0.8871 & 1.63 & 17.4 & 9.3 & 73.3 \\
\hline 3 & 550 & 3 & 101.4 & 173.6 & 1.49919 & 0.8868 & 1.62 & 17.1 & 10.2 & 72.7 \\
\hline 4 & 450 & 1 & 99.5 & 175.5 & 1.49488 & 0.8828 & 1.47 & 14.6 & 13.1 & 72.3 \\
\hline 5 & 450 & 2 & 97.6 & 177.4 & 1.49177 & 0.8795 & 1.44 & 12.7 & 15.3 & 72.0 \\
\hline 6 & 450 & 3 & 97.4 & 177.6 & 1.49141 & 0.8791 & 1.43 & 12.5 & 15.6 & 71.9 \\
\hline 7 & 350 & 1 & 100.6 & 174.4 & 1.49788 & 0.8863 & 1.59 & 16.3 & 11.5 & 72.2 \\
\hline 8 & 350 & 2 & 100.1 & 174.9 & 1.49701 & 0.8851 & 1.53 & 15.8 & 11.6 & 72.6 \\
\hline 9 & 350 & 3 & 100.0 & 175.0 & 1.49647 & 0.8845 & 1.50 & 15.5 & 12.0 & 72.5 \\
\hline
\end{tabular}

according to ASTM D7042. This Viscometer automatically calculates the kinematic viscosity of samples using the measured values of density and dynamic viscosity, and delivers the results based on ISO 3104 or ASTM D445, with the precision of 0.0001 for density and 0.001 for kinematic viscosity. The sulfur content of the samples was determined with ICP analyzer.

Regarding the fact that lubricating oil is generally produced by the processing of raffinate phase, am studying on the quality of lubricating oils should be done only by considering the raffinate phase. Physical properties of raffinate samples are tabulated in Table $\mathbf{2}$.

It is worth mentioning that the volume of all raffinate phases was very close to each other's. In the next step, physical properties of the raffinate samples were used to investigate the effect of agitation rate and settling time. The aromatic content, density, heat capacity and heating value of the samples were measured at different temperatures.

A liquid specific heat capacity meter (Kyoto Electronics Manufacturing Co., LTD., SHA-500 model) was used to measure the heat capacity of the samples. The heating value of raffinate samples was calculated based on ASTM D3523-92, Standard Test Method for Spontaneous Heating Values of Liquids and Solids.

\section{RESULTS AND DISCUSSION}

Mass transfer in a liquid-liquid extraction process is usually a slow phenomenon, meaning more time is needed for two phases to reach the equilibrium condition. Aromatic content of raffinate phase will be decreased when the settling time increases. The Rate of change of aromatic content was not uniform, so that the change in the amount of aromatic concentration, $\mathrm{C}_{\mathrm{A}}$, between 1 and $2 \mathrm{hrs}$ were measured to be more than that between 2 and 3hrs. Since the change in the amount of extraction of aromatic after $2 \mathrm{hrs}$ of settling time was not significant, thereby the $2 \mathrm{hrs}$ being selected as the optimum settling time.

A lower amount of aromatic compounds in the raffinate phases will result in having a better quality product. Figure 2 shows how $\mathrm{C}_{\mathrm{A}}$ is plotted against the settling time in different agitation rates.

In regard to the analysis of experimental samples, it can be seen that no linear trend can be found out between the agitation rate and the yield of extraction. Increasing the agitation rate will increase the amount of aromatics extracted until a certain point.

Figure 3 depicts that the maximum amount of extraction can be achieved for the agitation rate of 450 RPM. For the precise determination of agitation rate, most of the experimental runs were performed at $2 \mathrm{hrs}$ settling time and the agitation rate of $410,430,450,470$, and 490 RPM. Temperature and the ratio of solvent to feed were kept constant as the previous runs. Results are shown in Figure 4.

It was found that in the range of (430-435) RPM, the maximum extraction of aromatic can be reached.

\subsection{Effect of Rotation Rate of Density of Raffinate Samples}

As it was mentioned earlier, the raffinate samples after settling time of $2 \mathrm{hrs}$ have been considered the final lubricating base oil product. At the next step the density of the samples was measured at different 


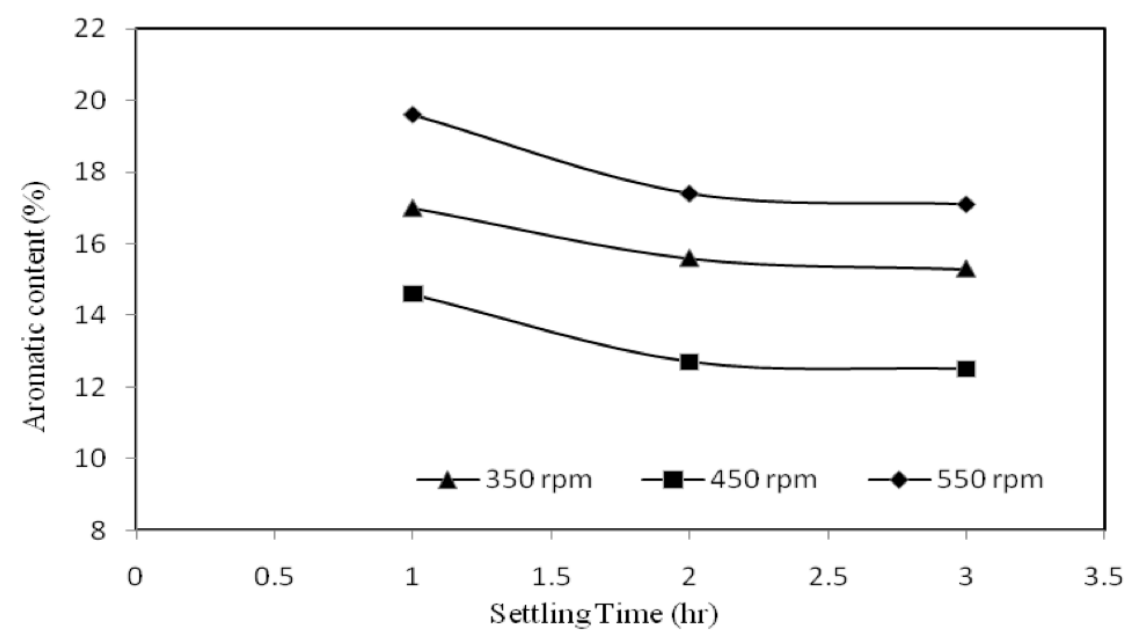

Figure 2: Relationship between aromatic content and settling time in different agitation rates.

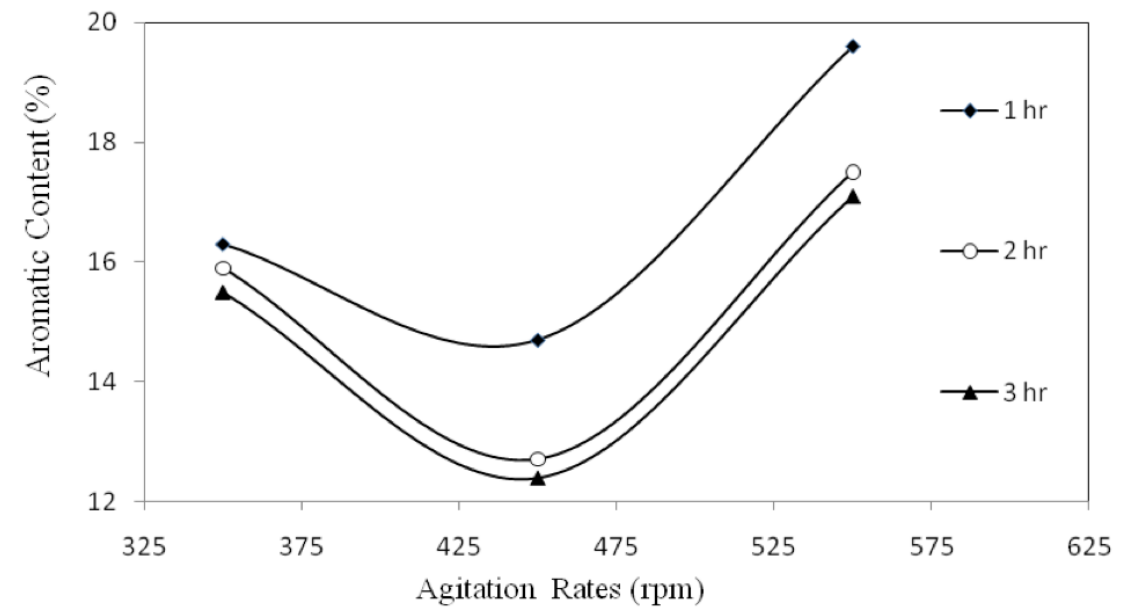

Figure 3: Relationship between aromatic content and agitation rate in different settling times.

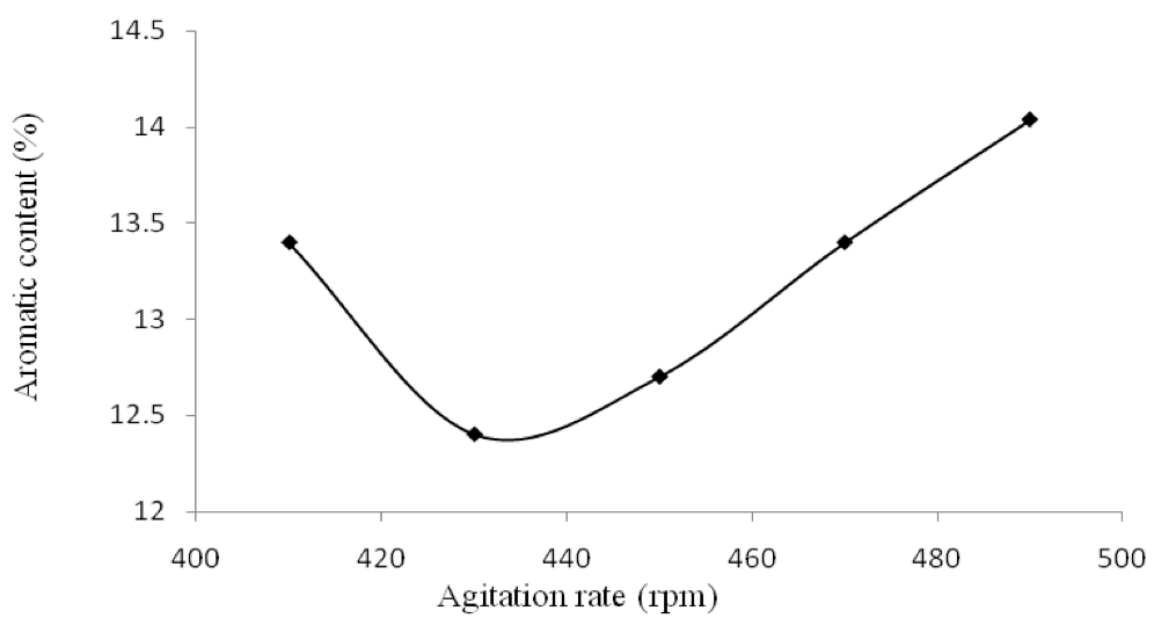

Figure 4: The relationship between aromatic content and agitation rate after $2 \mathrm{hrs}$ of settling time.

temperatures with results shown in Figure $\mathbf{5}$. It is seen that with an increase in the temperature of samples their densities were decreased dramatically with a linear trend. At all temperatures, density of the samples agitated with a rate of 450 RPM, were smaller than that of other samples. 


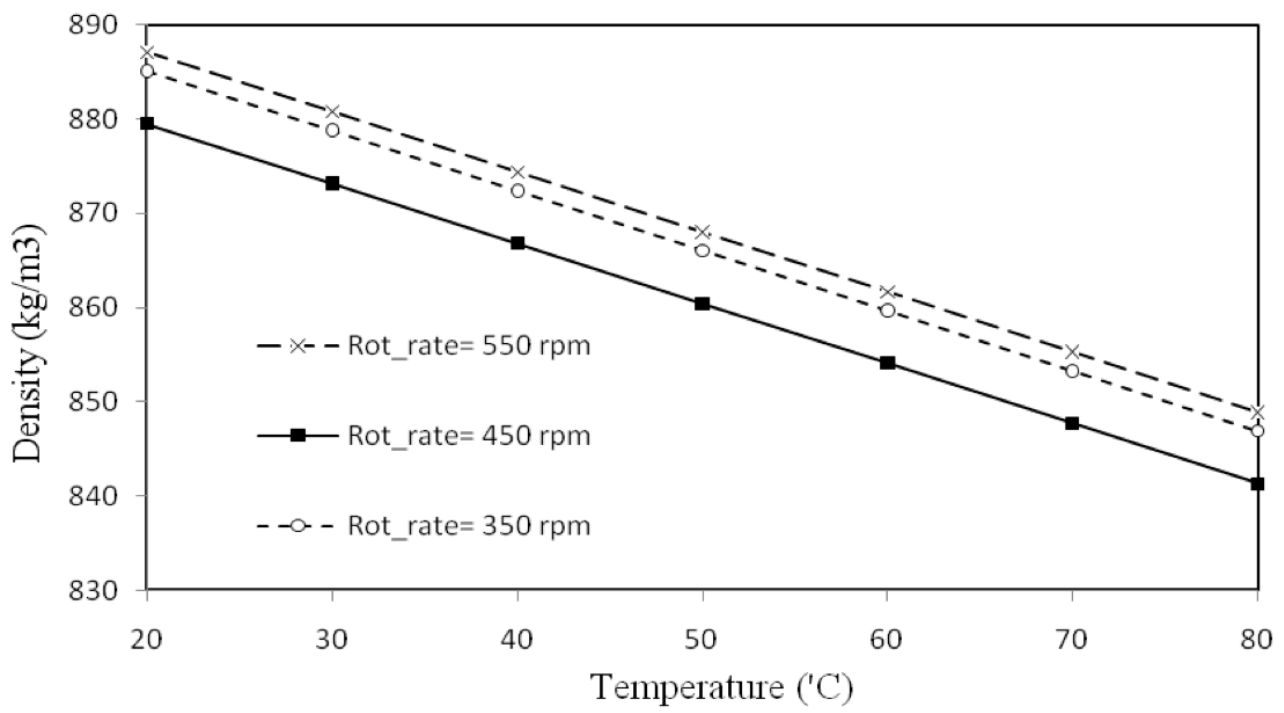

Figure 5: Density variation of raffinate samples with temperature.

\subsection{Effect of Rotation Rate on Heat Capacity of Raffinate Samples}

Heat capacity of test samples was measured at different temperatures and the results are shown in Figure 4. It can be seen that with an increase in the temperature, the heat capacity of samples will be decreased significantly. In the entire range of temperatures, the heat capacity of samples agitated under the rate of 450 RPM, was lower than that of others.

\subsection{Effect of Rotation Rate on Heating Value of the Samples}

Heating value of raffinate samples was measured accurately; the results are depicted in Figure 6. It was observed that samples under the agitation rate of 450
RPM have more heating values compared to the others. Figure 7 reveals that when the samples are produced under the agitation rate of 450 RPM, there is not a significant difference between the heating value of the samples between 2 and $3 \mathrm{hrs}$.

\section{CONCLUSION}

1. It was seen from the experimental tests that the increase of settling time will increase the yield of extraction of aromatics as well. At the first time interval, the rate of changes in the yield of extraction was more and it was reduced as time passes.

2. Increasing the agitation rate will result in an increase in the amount of extraction of aromatic from feed until an optimum point thereafter it

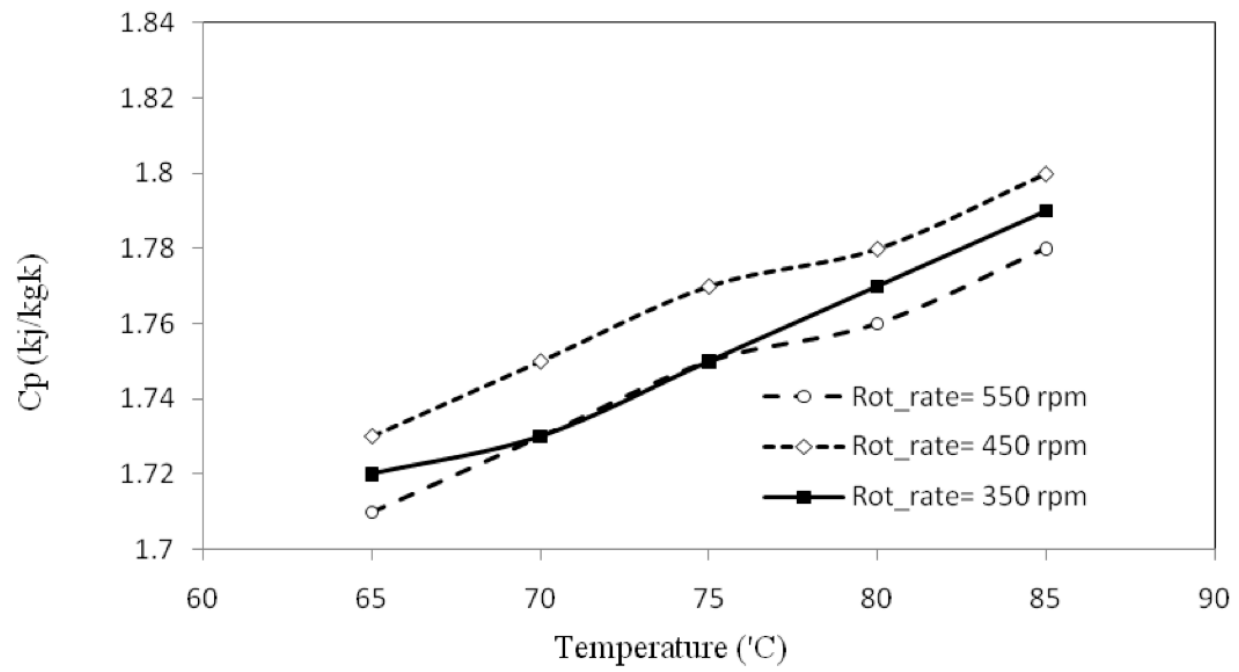

Figure 6: Heat capacity variation of raffinate samples with temperature. 


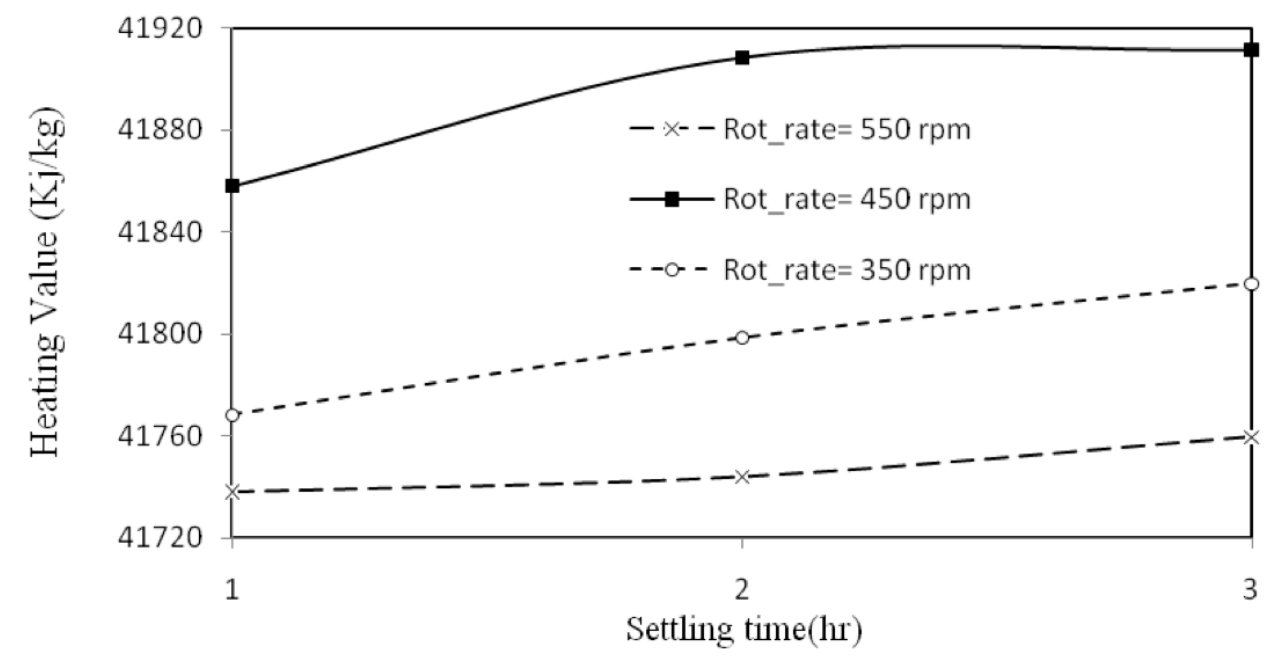

Figure 7: Heating value variation of the raffinate samples vs. settling time.

starts being lowered when agitation rate increases.

3. Based on the experimental results, the settling time of $2 \mathrm{hrs}$ and the agitation rate of $430 \mathrm{RPM}$ are proposed to be the optimum operational condition.

\section{REFERENCES}

[1] Willis G. Lubrication Fundamentals, second Ed. New York. (1984)

[2] Singh $\mathrm{H}$, Kishore $\mathrm{K}$. Solvent refining of medium viscosity distillate and changes in group chemical composition. J Appl Chem Biotechnol 1978; 28: 617-25.

[3] Sequeira A. Lubricant Base oil and Wax processing. Marcel Dekker,) New York (1994) pp. 81-2.

[4] Espada JJ, Coto B, Grieken R, Moreno JM. Simulation of pilot-plant extraction experiments to reduce the aromatic content from lubricating oil. Chem Eng Proc 2008; 47: 1398403.

http://dx.doi.org/10.1016/j.cep.2007.06.012

[5] Vakili-Nezhad GR, Modares H, Mansoori GA. Solvent extraction of aromatic components from lube-oil cut by nmethylpyrrolidone(NMP). Chem Eng Tech 1999; 22: 847-53. http://dx.doi.org/10.1002/(SICI)15214125(199910)22:10<847::AID-CEAT847>3.0.CO;2-P

[6] Nelson WL. Petroleum Refining Engineering, fourth ed.McGraw-Hill, New York, 1978.

[7] De Lucas A, Rodriguez L, Sanchez P, Carnicer A. Extraction of aromatic compounds from heavy neutral distillate lubricating oils by using furfural. Sep Sci Tech 1993; 28: 2465-77. http://dx.doi.org/10.1080/01496399308019749

[8] Mcketta JJ. Encyclopedia of Chemical processing and design, Marcel Dekker) New York (1989).

[9] Coto B, Grieken R, Pena JL, Espada JJ. A generalized model to predict the liquid-liquid equilibrium in the system of furfural + lubricating oils. Chem Eng Sci 2006; 61: 8028-39. http://dx.doi.org/10.1016/j.ces.2006.09.037
[10] Coto B, Grieken R, Pena JL, Espada JJ. A model to predict physical properties for light lubricating oils and its application to the extraction process by furfural. Chem Eng Sci 2006; 61: 4381-92. http://dx.doi.org/10.1016/j.ces.2006.02.009

[11] Rahman M, Mikitenko P, Asselineau L. Solvent extraction of aromatics from middle distillates. Chem Eng Sci 1984; 39: 1543-58.

http://dx.doi.org/10.1016/0009-2509(84)80083-4

[12] Elbashir NO, Zahrani SM, Abdul Mutalib MI, Abasaeed AE. A method of predicting effective solvent extraction parameters for recycling of used lubricating oils. Chem Eng Proc 2002; 41: 765-9.

http://dx.doi.org/10.1016/S0255-2701(02)00006-5

[13] El-Din OIS, Hassan SI, Taman AR, Farog AS. Recovery of waste lubricating oil by solvent extraction. Hungarian $\mathrm{J}$ Ind Chem 1987; 15: 357-64.

[14] Reis MA, Jernimo MS. Waste lubricating oil re-refining by solvent extraction flocculation. A scientific basis to design efficient solvents. Ind Eng Chem Res 1988; 27: 1222-8. http://dx.doi.org/10.1021/ie00079a023

[15] Chementator, solvent extraction process recycles waste oil. Chem Eng 1996; 103: 19.

[16] Hariu $\mathrm{OH}$, Sage RC. Crude split figured by computer. Hydrocarbon Processing 1960; 48: 143-8.

[17] Briesen $\mathrm{H}$, Marquradt $\mathrm{W}$. New approach to refinery process simulation with adaptive composition representation. AIChE J 2004; 50: 633-45. http://dx.doi.org/10.1002/aic.10057

[18] ASTM Annual Book of Standard, American Society for testing and Materials, vol. 5. West Conshohocken, 2003.

[19] Riazi MR, Daubert TE. Prediction of molecular-type analysis of petroleum fraction and coal liquids. Ind Eng Chem Proc 1986; 25: 1009-15. http://dx.doi.org/10.1021/i200035a027

[20] ASTM Annual Book of Standard, Calculation of Carbon Distribution and Structural Group Analysis of Petroleum Oils by the n-d-M Method, West Conshohocken, 2004.

[21] ASTM Annual Book of Standard, Estimation of Mean Relative Molecular Mass of Petroleum oils from Viscosity Measurements, West Conshohocken, 2004. 